\title{
ƯNG DỤNG GIS TRONG CÔNG TÁC QUẢN LÝ NHÀ NƯỚC VỀ CẤP ĐẤT TỔ CHỨC TẠI GIA LAI
}

ThS. TRÀN QUÓC KHÁNH

Sở Tài nguyên Môi trường tỉnh Gia Lai

\section{Mở đầu}

Công tác giao đất, cấp đất, thu hồi, cho thuê đất của các tổ chức (sau đây gọi chung là cấp đất) trên địa bàn tỉnh Gia Lai được thực hiện từ khi có Luật đất đai năm 1993 ra đời, cùng với sự ra đời của ngành Quản lý đất đai (nay là ngành Tài nguyên và Môi trường). Quá trình thực hiện công tác cấp đất từ năm 1994 đến nay đã cấp hơn 2.405 hồ sơ với diện tích trên 267.127,7 ha, nhưng hệ thống bản đồ, hồ sơ cấp đất, thực trạng lưu trữ còn nhiều cấp cập. Vì vậy cần có một phần mềm nhằm nâng cao hiệu quả quản lý công tác cấp đất tổ chức cho toàn tỉnh; tránh cấp chồng chéo giữa các dự án; hoàn thiện các hồ sơ cấp đất để phục vụ công tác quản lý đối với các dự án đã, đang và sẽ cấp đất; nhanh chóng cung cấp các thông tin của dự án theo yêu cầu của người sử dụng; hiện đại hóa công tác lưu trữ, trích xuất, in ấn hồ sơ.

\section{1. Ứng dụng của GIS trong quản lý đất đai}

GIS có các chức năng cơ bản là nhập và bổ sung dữ liệu, chuyển đổi dữ liệu, lưu trữ dữ liệu, điều khiển dữ liệu, hiển thị dữ liệu theo cơ sở địa lý và đưa ra quyết định. GIS được thiết kế như một hệ thống chung để quản lý dữ liệu không gian, có nhiều ứng dụng trong việc phát triển đô thị và môi trường tự nhiên như: quy hoạch đô thị, điều hành hệ thống công ích, giám sát vùng biển .v.v... Trong phần lớn các lĩnh vực này, GIS đóng vai trò như là một công cụ hỗ trợ quyết định cho việc lập kế hoạch hoạt động. Hệ thống GIS về đất đai được gọi bằng thuật ngũ chuyên dụng trong tiếng Anh là Cadastra. Ở đây, các thửa đất được lưu trữ dưới dạng là các đối tượng hình học (toạ độ các đỉnh của thửa đất, cấu trúc topo, diện tích), các thông tin về chủ sở hữu, các hồ sơ pháp lý, tính chất thổ nhưỡng của đất, .v.v... đều được gắn liền với từng thửa đất tương ứng. Bộ Tài nguyên và Môi trường cũng đang triển khai trên toàn quốc trong công tác xây dựng, hoàn thiện hệ thống hồ sơ địa chính.

\section{2. Ứng dụng ArcGIS trong công tác} quản lý Nhà nước về cấp đất tổ chức tại Gia Lai

ArcGIS là một bộ phần mềm của hãng ESRI - Mỹ: Là một bộ tích hợp các sản phẩm phần mềm - một bộ bao gồm nhiều phần mềm với mục tiêu xây dựng một hệ thống thông tin địa lý (GIS) hoàn chỉnh. Bộ phần mềm này có thể thực hiện các chức năng về GIS trên máy trạm, server, dịch vụ web hay thiết bị di động. Với các kỹ thuật này cho phép người dùng có được các công cụ quản lý một hệ thống GIS phức tạp.

\subsection{Quy trình công nghệ thành lập bản đồ cấp đất tổ chức}

Bước 1: Thu thập, đánh giá nguồn dữ liệu;

Bước 2: Thiết kế thư mục lưu trữ bản đồ; 
phân lớp các đối tượng nội dung và xây dựng thư viện ký hiệu bản đồ; xác định cơ sở toán học cho bản đồ;

Bước 3: Xây dựng, chuẩn hóa hệ thống bản đồ (số hóa, chuẩn hóa dữ liệu, sơ đồ, bản đồ cấp đất):

- Vec tơ hoá các giá trị trị đo;

- Trích lục thửa đất, cập nhật nhãn thửa;

- Đưa trích lục lên bản đồ chung toàn tỉnh;

- Chuyển dữ liệu về hệ quy chiếu và hệ tọa độ quốc gia Việt Nam VN-2000;

Bước 4: Cập nhật, bổ sung, hoàn thiện hệ thống hồ sơ:

- Số hóa một số văn bản quan trọng như Quyết định, Tờ trình, Biên bản, Ý kiến các cấp ngành;

- Cập nhật, bổ sung, hoàn thiện hệ thống hồ sơ đã cấp đất tổ chức chung cho toàn tỉnh với 20 trường dữ liệu; gồm: số thứ tự; tên tổ chức; địa chỉ tổ chức; quyết định thành lập hoặc giấy phép ĐKKD; số tờ bản đồ địa chính (nếu có); số thửa địa chính (nếu có); diện tích pháp lý; địa chỉ thửa đất; ngày bắt đầu sử dụng; quyết định cấp; hợp đồng; thời hạn; nguồn gốc sử dụng đất; mục đích sử dụng đất; số GCNQSDĐ; số vào sổ cấp GCN; tài sản trên đất; mã vạch; ghi chú.

Bước 5: Trình bày, biên tập bản đồ;

Bước 6: Nghiệm thu bản đồ trên máy tính;

Bước 7: In bản đồ ra giấy;

Bước 8: Ghi dữ liệu bản đồ vào đĩa $C D$; Nghiệm thu bản đồ trên đĩa $C D$ và bản đồ giấy; Đóng gói và giao nộp sản phẩm.

2.2. Ứng dụng chủ yếu trong công tác quản lý Nhà nước

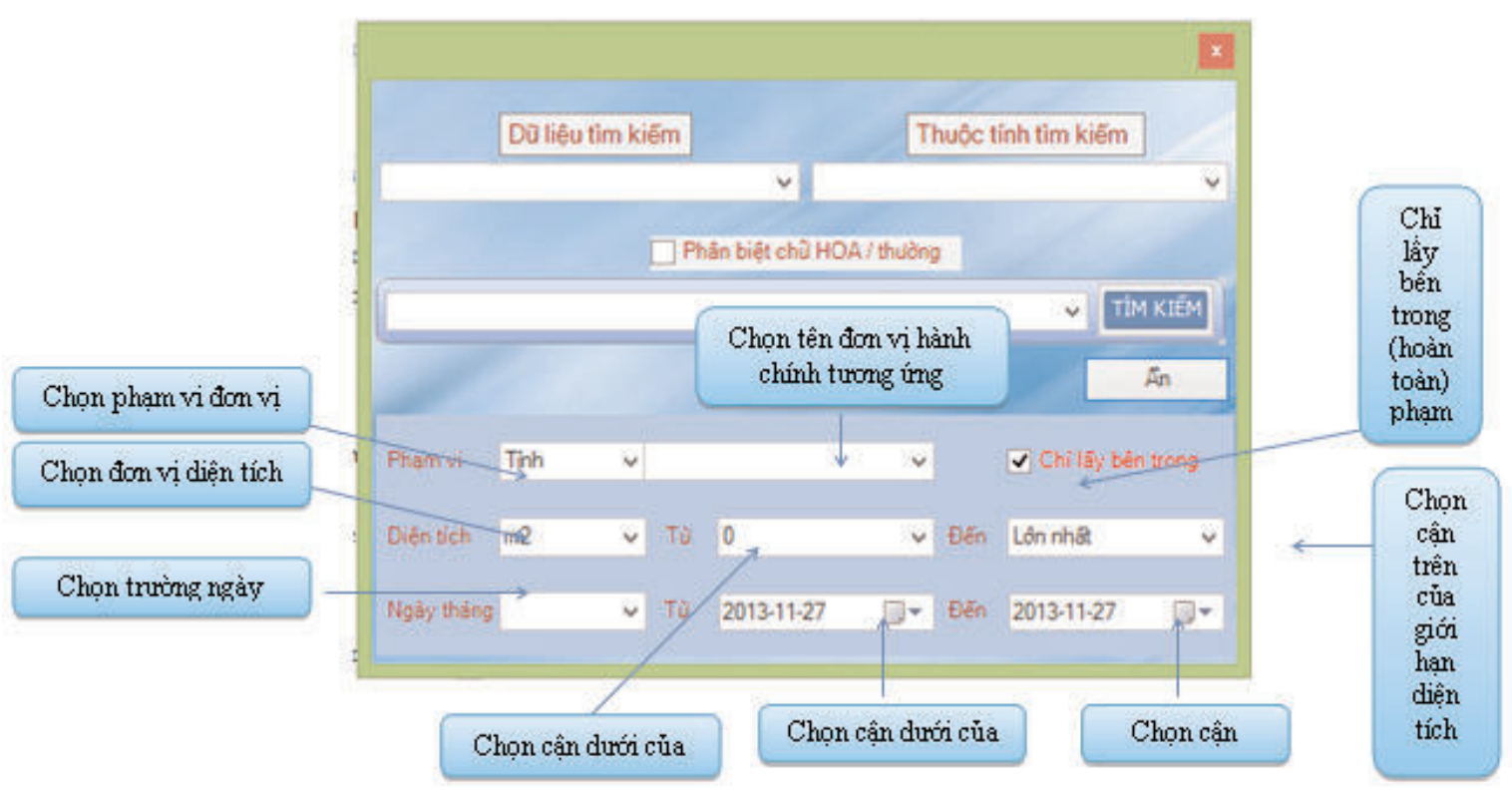

Hình 1: Tìm kiếm trên cơ sở dữ liệu 


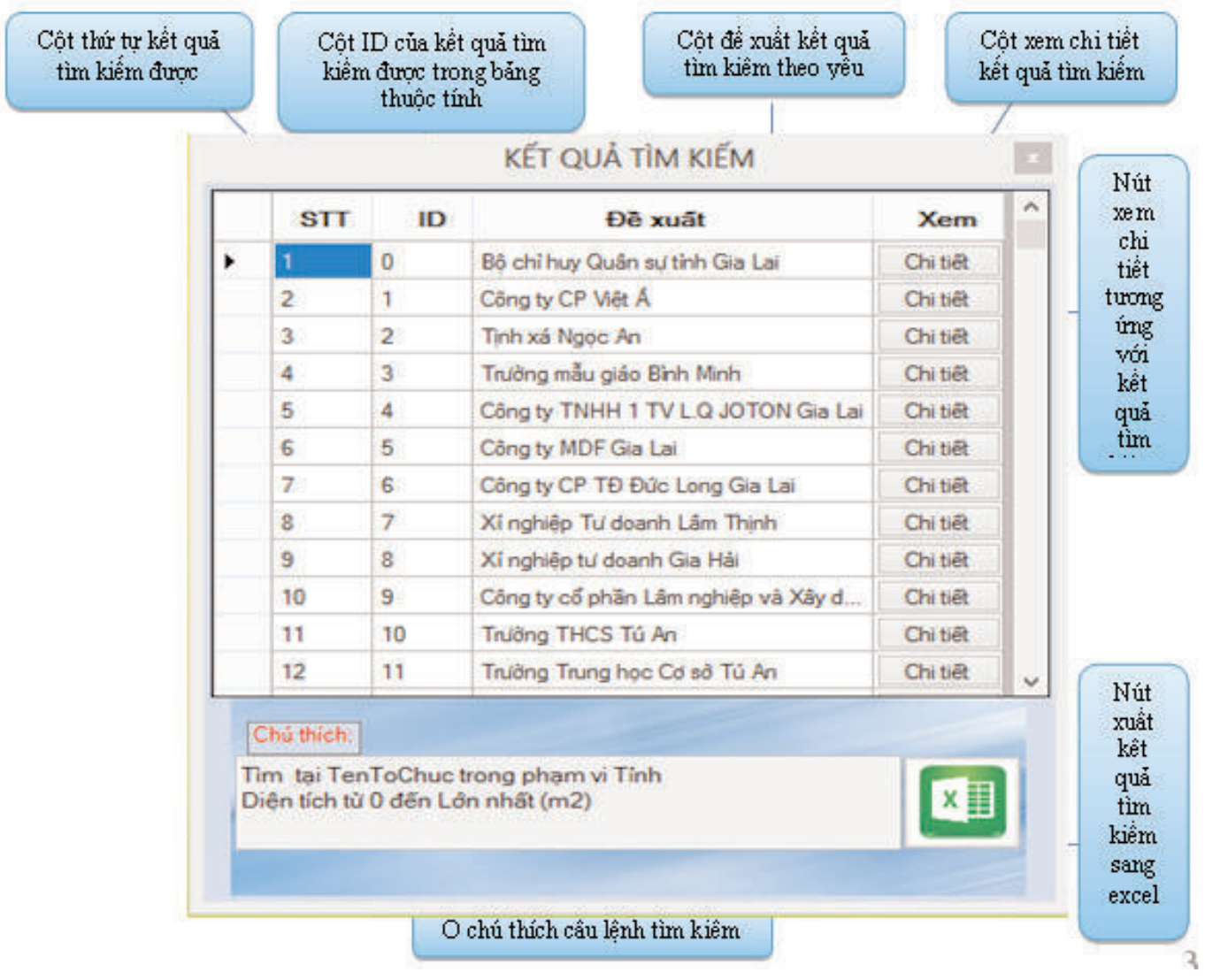

Hình 2: Kết quả tìm kiếm

\begin{tabular}{|c|c|c|c|}
\hline & \multicolumn{2}{|c|}{ CHITIETT THÜA ĐĂT } & \multirow{2}{*}{$\frac{x}{n}$} \\
\hline & Ten Thuoge Tinh & Gia Tri & \\
\hline & Quyet Dinh & & \\
\hline & Thoithan & Lău dă & \\
\hline & NguonGocSD & 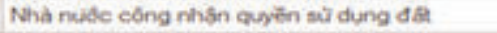 & \\
\hline & NguonGooCT & Dât cod sd Gib́o duc - Dào tso không kinh doart & \\
\hline & MueDichSD & DGD & \\
\hline & SoGCN & AMA 820731 ngaty $23 / 9 / 2009$ & \\
\hline & SoVaoSoCap & T 00651 & \\
\hline & TaiSanTren & & \\
\hline & Ghichus & & \\
\hline & HopDong & & \\
\hline & Shape_Leng & 304.398004185 & \\
\hline & Shape_Area & 57037546804 & \\
\hline & NoayBatDaw & $9 / 23 / 2008$ 12:00:00 AM & \\
\hline+ & Detka_S (ha) & 8.75468040000032 & $\checkmark$ \\
\hline$<$ & & & \\
\hline
\end{tabular}

Hình 3: Thông tin chi tiết của một thửa đất 
a) Tìm kiếm, tổng hợp theo yêu cầu: Đối với các yêu cầu của quản lý Nhà nước như tìm với các đối tượng là đất quốc phòng có diện tích trên 50 ha; hay đất các cơ sở giáo dục với diện tích trên 2 ha... (Xem hình 1)

Ta có thể chọn các đối tượng quản lý như theo đơn vị hành chính (có thể chỉ lấy trong hoặc ngoài đơn vị hành chính yêu cầu); theo đơn vị diện tích (chọn khoảng diện tích từ cận trên và cận dưới); theo ngày tháng năm cấp đất (chọn từ ngày tháng năm nào đến ngày tháng năm nào)... (Xem hình 2,3$)$

Ta có thể xem chi tiết đến từng thửa đất với các thông tin như: số thứ tự; tên tổ chức; địa chỉ tổ chức; quyết định thành lập hoặc giấy phép ĐKKD; số tờ bản đồ địa chính (nếu có); số thửa địa chính (nếu có); diện tích pháp lý; địa chỉ thửa đất; ngày bắt đầu sử dụng; quyết định cấp; hợp đồng; thời hạn; nguồn gốc sử dụng đất; mục đích sử dụng đất; số GCNQSDĐ; số vào sổ cấp GCN; tài sản trên đất; mã vạch; ghi chú...

Việc tổng hợp các đối tượng theo yêu cầu tìm kiếm ví dụ như "các loại đất giao cho mục đích trồng cao su trên 50 ha, giao từ 2008 đến nay" để từ đó tổng hợp trích xuất sang biểu bảng Excel, hay Word thông dụng để lập báo cáo theo chuyên đề với yêu cầu của các nhà quản lý. gian:

b) Quản lý đối với các đối tượng không

Việc thực hiện chỉnh lý, hiện chỉnh, cập nhật với yêu cầu bảo mật chỉ được thực hiện bởi cơ quan có thẩm quyền (Sở Tài nguyên và Môi trường);

Đối với công tác quản lý của người dùng với yêu cầu quản lý các đối tượng bản đồ:

c) Trích xuất hồ sơ:

Để đảm bảo tính bảo mật đối với công tác lưu trữ hồ sơ cấp đất tổ chức, một số văn bản quan trọng như Quyết định, Tờ trình; Biên bản; Ý kiến các cấp ngành... không phải lấy hồ sơ gốc. Trong quá trình thực hiện đối với mỗi thửa đất tiến hành số hóa tất cả các văn bản có liên quan để có thể trích dẫn, trình chiếu, hay in ấn để phục vụ công tác quản lý.

\section{Phương hướng phát triển ứng dụng}

Công tác cấp đất cho các tổ chức theo Luật đất đai 2003 do cấp tỉnh quản lý (đầu mối là Sở Tài nguyên và Môi trường), tuy nhiên đối với mỗi hồ sơ đều phải có sự xác nhận, sự phối hợp của các cấp chính quyền, các ngành có liên quan. Vì vậy công tác phải được thực hiện dưới hình thức ủy quyền cho các huyện, thị xã, thành phố (trực thuộc tỉnh) trên cơ sở thống nhất dữ liệu đầu vào theo một quy chuẩn chung.

Đối với việc tra cứu, sử dụng đối với từng huyện, thị xã, thành phố có thể chuyển giao phần mềm, bản đồ và hồ sơ địa chính đối với các hồ sơ đã cấp đất tổ chức (khi đã hoàn thiện và được sự cho phép của cấp có thẩm quyền).

Cùng với sự phát triển của công nghệ thông tin, GIS cho phép chia sẻ thông tin thông qua mạng toàn cầu bằng cách kết hợp GIS và Web. ArcGIS có thể thực hiện các chức năng về GIS trên máy trạm, server, dịch vụ web hay thiết bị di động. Các kỹ thuật này cho phép người dùng có được các công cụ quản lý một hệ thống GIS phức tạp. Vì thế, việc nghiên cứu ứng dụng GIS trên cơ sở mã nguồn mở sẽ mang lại khả năng chia sẻ thông tin địa lý rộng rãi cho các ngành, đưa ra các giải pháp về bản đồ trực tuyến, truy xuất các thông tin trực tuyến và khả năng xây dựng ứng dụng bản đồ trên cơ sở mã nguồn mở.

\section{Kết luận}

Ứng dụng công nghệ GIS đã giúp cho 
công tác quản lý Nhà nước về cấp đất tổ chức được thực hiện một cách khoa học, thay thế cho phương thức quản lý truyền thống trước đây. Công tác quản lý, cập nhật, chỉnh lý các biến động thường xuyên được thực hiện trên máy tính sẽ giúp cho công tác quản lý nhà nước về đất đai thống nhất, đồng bộ từ cấp tỉnh đến cấp xã. Đây là tiền đề quan trọng để hướng đến hoàn thiện hệ thống thông tin về đất đai hiện đại, minh bạch, phục vụ việc chia sẻ thông tin nhanh cho các cơ quan của Nhà nước, đáp ứng nhu cầu tra cứu thông tin đất đai cho người dân và doanh nghiệp qua môi trường mạng máy tính./.O

Ngày nhận bài: 27/02/2014.

\section{BÀN VỀ PHÉP CHIẾU......}

(Tiếp theo trang 33)

2. Phương án sử dụng phép chiếu UTM với $\mathrm{k}=0.9999$ và kinh tuyến trục địa phương cho bản đồ HTSDĐ từ cấp tỉnh trở xuống đảm bảo biến dạng diện tích tối ưu đối với tất cả các tỉnh, thuận lợi cho thành lập bản đồ hiện trạng sử dụng đất từ bản đồ địa chính chính quy cũng như sử dụng kết hợp bản đồ các tỷ lệ và các cấp trong công tác quản lý đất đai tại địa phương.

3. Các bản đồ chuyên đề trong phạm vi đơn vị hành chính cấp tỉnh tỷ lệ 1:500.000 và lớn hơn nên được thành lập ở phép chiếu UTM với $\mathrm{k}=0.9999$ và kinh tuyến trục địa phương. $\mathrm{O}$

\section{Tài liệu tham khảo}

[1]. Thông tư 973/2001/TT-TCĐC của
Tổng cục địa chính ngày 20/06/2001 về hướng dẫn áp dụng hệ quy chiếu và hệ tọa độ quốc gia VN-2000.

[2]. Quy định về thành lập bản đồ hiện trạng sử dụng đất ban hành kèm Quyết định số 22/2007/QĐ-BTNMT ngày 17/02/2007 của Bộ trưởng Bộ Tài nguyên và Môi trường.

[3]. Thông tư 15/2013/TT-BTNMT ngày 15/06/2013 của Bộ Tài nguyên và Môi trường Quy định kỹ thuật lập bản đồ tài nguyên nước dưới đất tỷ lệ 1:50.000.

[4]. Đồng Thị Bích Phương. Phép chiếu Chebyshev dùng cho bản đồ Việt Nam. Tạp chí Địa chính, số 5-2006. 0

\section{Summary}

\section{About projection for land use map}

\section{Dong Thi Bich Phuong}

\section{Vietnam Institute of Geodesy and Cartography}

This paper clarifies a number of factors affecting the choice of map projection for landuse map and proposes using transverse mercator projection with $\mathrm{k}=0.9999$ and local central meridian for landuse map of provincial, district and commune level. $\bigcirc$

Ngày nhận bài: 08/12/2013. 